\title{
The Many Therapeutic Applications of Nigella sativa - A Review of Literature
}

\author{
Uzma Iqbal Belgaumi ${ }^{1}$, Satish Patil², Jotsna Mohanlal Gandhi ${ }^{3}$, Amol Somnath Shete ${ }^{4}$
}

\begin{abstract}
${ }^{1}$ Department of Oral Pathology and Microbiology, School of Dental Sciences, Krishna Institute of Medical Sciences, Deemed to Be University, Karad, Maharashtra, India. ${ }^{2}$ Department of Microbiology, Krishna Institute of Medical Sciences, Deemed to Be University, Karad, Maharashtra, India. ${ }^{3}$ Department of Pharmacy, Krishna Institute of Pharmacy, Krishna Institute of Medical Sciences, Deemed to Be University, Karad, Maharashtra, India. ${ }^{4}$ Department of Pharmacy, Krishna Institute of Pharmacy, Krishna Institute of Medical Sciences, Deemed to Be University, Karad, Maharashtra, India.
\end{abstract}

\section{ABSTRACT}

\section{BACKGROUND}

Medicinal plants have been used since ancient times as therapeutic agents for treatment of various diseases and ailments. Description of medicinal uses of plants are found abundantly in ancient papyrus writings from various civilizations. Indigenous cultures even today use herbs in their healing rituals. Medicinal plants are considered as rich sources of phytochemical ingredients which play a vital role for the development of new drugs.

Nigella sativa ( $N$. sativa) is commonly known as Black seed or Kalongi, sometimes also referred to as miracle herb has been studied extensively for its various medicinal benefits. Apart from being used as a spice it is also used in various traditional systems of medicine including Ayurveda due to its healing properties in the treatment of various diseases. The seeds of Nigella sativa and their oil have been widely used for centuries in the treatment of various ailments throughout the world. And it is an important drug in the Indian traditional system of medicine like Unani and Ayurveda. It has been extensively studied for its biological activities and therapeutic potential and has been shown to possess wide spectrum of activities like diuretic, antihypertensive, antidiabetic, anticancer, immunomodulatory, analgesic, antimicrobial, anthelmintic, analgesic, antiinflammatory, spasmolytic, bronchodilator, gastroprotective, hepatoprotective, renal protective and antioxidant properties. Most of the therapeutic properties of this plant are due to the presence of thymoquinone (TQ) which is a major active chemical component of the essential oil.

Research into its therapeutic potential has highlighted its use due to its efficacy as an antioxidant, for glycaemic control, anticancer, antimicrobial and for its various other potential health benefits. Experimental studies have reported that Nigella sativa Oil and Nigella sativa extracts have anti-microbial activity against a wide range of microbes, especially multiple-antibiotic resistant bacteria. The current article tries to present a comprehensive and yet short review of this miraculous herb and its various applications in medicine especially in the backdrop of emerging antibiotic resistant superbugs.

\section{KEY WORDS}

Herbal Medicine, Medicinal Herbs, Nigella sativa, Black Cumin, Kalonji
Corresponding Author: Uzma Iqbal Belgaumi, Associate Professor, Department of Oral Pathology \& Microbiology, School of Dental Sciences, Krishna Institute of Medical Sciences, Deemed to Be University, Karad, Maharashtra, India. E-mail:uibelgaumi@gmail.com

DOI: $10.14260 /$ jemds/2020/469

How to Cite This Article:

Belgaumi UI, Patil S, Gandhi JM, et al. The many therapeutic applications of Nigella sativa- a review of literature. J. Evolution Med. Dent. Sci. 2020;9(30):2151-2157, DOI: 10.14260/jemds/2020/469

Submission 30-03-2020,

Peer Review 14-06-2020,

Acceptance 22-06-2020,

Published 27-07-2020.

Copyright (C) 2020 JEMDS. This is an open access article distributed under Creative Commons Attribution License [Attribution 4.0 International (CC BY 4.0)] 


\section{BACKGROUND}

Ancient papyrus writings as early as 3000 BC, describe medicinal uses of plants. Indigenous cultures have used herbs in their healing rituals. On the other hand, developed traditional medical systems like Siddha, Ayurveda, Unani, and Traditional Chinese Medicine use herbal therapies successfully. ${ }^{1}$

About two centuries ago, our medicinal practices were largely dominated by plant-based medicines. But, the medicinal use of herbs went into a rapid decline in the West since the introduction of more predictable synthetic drugs with their fast effects and easy availability. ${ }^{2}$

A German philosopher Friedrich Nietzsche's once said, "What does not kill me makes me stronger." Today we all are aware of problems that are related to the development of antibiotic resistance, the emergence of superbugs and the grave implications this can have on our existence today and in the future. Tom Frieden has said that "It is the end of the road for antibiotics unless we act urgently." Herbal medicines have been used since time immemorial for various advantages that they possess but the problem of antibiotic resistance has added a great deal of interest in the research of these compounds. They can provide a potential alternative to this growing problem.

Ethnopharmacology or Herbal medicine or Phytomedicine- Farnsworth and Bingel, 1977 in their book claimed that plant-based drugs have contributed revolutionarily to modern therapeutics. Like, vinblastine from the Catharanthus rosesus is successfully used in treating Hodgkins, choriocarcinoma, non-Hodgkin's lymphomas, leukemia in children, testicular, and neck cancer. ${ }^{3}$

Miller, 1998 said that with the advancements of scientific methods, the herbal medicines could find place in research and documented for effective use as drugs. Furthermore, in the 1960 s, with concerns over the toxic and iatrogenic effects of conventional medicine resulted in desire for safer and economically cheaper drugs to promote "natural health." Thus, afterwards, there has been a shift in universal trend from synthetic to herbal medicines. Moreover, herbal medicine received a worldwide boost when the WHO exhilarated developing countries to use traditional plant medicine to accomplish needs unmet by modern systems. ${ }^{4}$

Vickers and Zollman, in 1999 quoted that it has been reported that during 1950-70 about 100 new drugs based on plants were introduced in the US pharmaceutical industry including deserpidine, rescinnamine, reserpine, vinblastine, and vincristine. ${ }^{5}$

Leslie, in 2000 stated that Medicinal plants play a vital role for the development of new drugs. According to WHO, nearly $25 \%$ of the modern medicines have been derived from plants being used in traditional medicine. Many others are synthetic analogs fabricated on model compounds isolated from plants. And now WHO has recognized herbal medicine as a crucial component of primary health care. ${ }^{6}$

Fabricant and Farnsworth, 2001 in their article state that WHO has reported that 4 billion people $(80 \%$ of the world's population) use herbal medicines for one or other aspect of primary health care. ${ }^{7}$
Maurya et al., 2008 claimed that the use of such compounds has reduced the risk of many human diseases including cardiovascular diseases, hepatorenal diseases, diabetes, cancers, and neurodegenerative disorders. Additionally, plants are bestowed with several other pharmacological characters such as antioxidant, antiviral, antimicrobial, and antiparasitic for human use. Especially, alkaloids reported to possess an antispasmodic, antimalarial, analgesic, and diuretic activities; terpenoids are known for their antiviral, anthelmintic, antibacterial, anticancer, antimalarial, and antiinflammatory properties; glycosides are reported for antifungal and antibacterial properties; phenols and flavonoids have an antioxidant, antiallergic, and antibacterial also stated that properties; and saponins have shown antiinflammatory and antiviral activities. ${ }^{8}$

Martinez et al., 2008 the pharmacological effects of plants are due to the presence of metabolites, which are organic compounds and classified into primary and secondary metabolites. Primary metabolites such as glucose, starch, polysaccharide, protein, lipids, and nucleic acids are beneficial for growth and development of the human body. More importantly plants also produce secondary metabolites including alkaloids, flavonoids, saponins, terpenoids, steroids, glycosides, tannins, volatile oils, etc. to protect plants against microbial infections or invasions by pests. The therapeutic efficacy of plants is because of these secondary metabolites and these are actually termed as "phytocompounds." Which are pharmacologically active ingredients and are exploited as drugs because of their therapeutic properties. ${ }^{9}$

WHO, 2008 report states that Ethnopharmacology or Herbal medicine or Phytomedicine is the use of plants for medicinal and therapeutic purpose for curing of diseases and improve human health. World Health Organization (WHO) has defined herbal medicines as finished labelled medicinal product that contain an active ingredient, aerial, or underground parts of the plant or other plant material or combinations. ${ }^{10}$

Evidenced-based research conducted in herbal medicine over the years has resulted in a paradigm shift toward therapeutic standardization of herbal drugs. Their efficacies have been supported and confirmed through many in vitro and in vivo clinical trials.

\section{NIGELLA SATIVA}

Nigella sativa Linn. is an annual herbaceous flowering plant belonging to the family Ranunculaceae. Nigella sativa is native to south and south west Asia. Nigella sativa is widely cultivated in India, Mediterranean countries, Europe, and Western Asia. It grows $20-30 \mathrm{~cm}$ tall with finely divided, linear leaves. Flowers are usually pale blue and white in colour with 5-10 petals. In its natural form, the flowers are bluish with a variable number of sepals and are characterized by the presence of nectaries. The gynoecium is composed of a variable number of multiovule carpels, developing into a follicle after pollination, with single fruits partially connected to form a capsule-like structure. The fruit is a large and inflated capsule composed of three to seven united follicles, each 
containing seeds. The seeds of Nigella sativa are small in size (1-5 mm), with corrugated integument. ${ }^{11}$

The seeds are used extensively as a spice for flavouring purposes, especially bakery products and cheese. Seeds of Nigella sativa are used in the preparation of a traditional sweet dish and eaten with honey and syrup as well as for sprinkling on bread. ${ }^{12,13}$

\section{Scientific Classification \\ 1. Kingdom: Plantae \\ 2. Division: Magnoliophyta \\ 3. Order: Ranunculales \\ 4. Family: Ranunculaceae \\ 5. Genus: Nigella \\ 6. Species: sativa ${ }^{14}$}

\section{Nigella sativa Composition}

Takruri et al, 1998 found that Nigella sativa contains $216 \mathrm{~g}$ protein, $406 \mathrm{~g}$ fat, $45 \mathrm{~g}$ ash, $84 \mathrm{~g}$ fiber, $249 \mathrm{~g}$ free nitrogen extract, $38 \mathrm{~g}$ moisture, $105 \mathrm{mg}$ iron, $18 \mathrm{mg}$ copper, $60 \mathrm{mg}$ zinc, $527 \mathrm{mg}$ phosphorus, $1860 \mathrm{~m}$ calcium, $15.4 \mathrm{mg}$ thiamine, $57 \mathrm{mg}$ niacin and $160 \mu \mathrm{g}$ folic acid per Kg. ${ }^{15}$

Cheikh R et al, 2007 evaluated physicochemical properties of two Nigella seed varieties, having a Tunisian and Iranian origin. Physical and chemical analyses of crude oils extracted from the seeds by a cold solvent method were also performed. The following results (on a dry-weight basis) were obtained for Tunisian and Iranian varieties, respectively: protein $26.7 \%$ and $22.6 \%$, oil $28.48 \%$ and $40.35 \%$, ash $4.86 \%$ and $4.41 \%$, and total carbohydrate $40.0 \%$ and $32.7 \%$. The major unsaturated fatty acids were linoleic acid (50.3-49.2\%), followed by oleic acid (25.0-23.7\%), while the main saturated fatty acid was palmitic acid (17.2-18.4\%). Myristic, myristoleic, palmitoleic, margaric, margaroleic, stearic, linolenic, arachidic, eicosenoic, behenic and lignoceric acids were also detected. ${ }^{16}$

Sun L et al, 2015, in their study found four phenolic compounds, including two new ones, Nigephenol A and B, and a new natural product, Nigephenol $C$, that were isolated from the seeds of Nigella glandulifera (one of the species growing in China). Their structures were elucidated on the basis of spectroscopic analyses. All compounds were evaluated by MTT method for in vitro cytotoxicity against four human cancer cell lines (Bel7402, HepG2, HCT- 8 and A549). The results revealed that Compounds 1-4 showed more selective activities against HepG2 cells, and that Compound 2 showed significant inhibitory effects against four human tumour cell lines with IC50 values comparable to those of 5-fluorouracil. ${ }^{17}$

Chen et al, 2017, found three novel norditerpenoid alkaloids. ${ }^{1-3}$ and one pyrroloquinoline alkaloid, ${ }^{4}$ possessing new skeletons with highly conjugated systems. The four alkaloids were isolated from $N$. glandulifera seed by using high-speed counter current chromatography (HSCCC). In the recent another paper reported by Chen et al., two new alkaloids, nigellisoquinomine (1) with a novel pyrroloisoquinoline skeleton, and nigellapyrrolidine (2) possessing a rare glycosylated pyrrolidine moiety were isolated from the seeds of $N$. glandulifera. ${ }^{18}$

Saxena et al. 2017 conducted a study to explore the suitability of Nigella sativa L. oil for human consumption on the basis of fatty acid (FA) composition in twenty-three selected genotypes. Total oil content ranged from 147 to 270 $\mathrm{ml} / \mathrm{Kg}$. Eleven fatty acids including palmitic, oleic, and linoleic acids were found during fatty acid methyl esters (FAME) analysis. Linoleic acid was major contributor in the range of $608.9 \mathrm{ml} / \mathrm{l}$ to $713.9 \mathrm{ml} / \mathrm{l}$. Saturated fatty acids ranged from 121 to $181 \mathrm{ml} / \mathrm{l}$ in genotype $\mathrm{AN}-23$ and $\mathrm{AN}-3$, respectively. Significant genetic variation was observed with respect to mono-unsaturated fatty acids. Poly-unsaturated fatty acid being dominant existed in the range of 651 to $771 \mathrm{ml} / \mathrm{l}^{19}$

Arroo et al, 2018 in their review stated that Thymoquinone is the main ingredient of the essential oil extracted from the seeds of Nigella sativa L. (Ranunculaceae). The monoterpene is considered to be the active pharmaceutical ingredient in the seeds, which have traditionally been highly prized for their medicinal properties. The compound has been the focus of a considerable number of pharmacological investigations and has been reviewed regularly for its action against a variety of inflammatory diseases, its effect on metabolic syndrome, and its potential anticancer properties. ${ }^{20}$

\section{MEDICINAL USES OF NIGELLA SATIVA}

Ramadan et al, 2003 in their study found that crude Nigella sativa oil and its fractions (neutral lipids, glycolipids, and phospholipids) showed potent in vitro radical scavenging activity that is correlated well with their total content of polyunsaturated fatty acids, unsaponifiables, and phospholipids, as well as the initial peroxide values of crude oils. ${ }^{21}$

Kalus et al, 2003 administered Nigellone (a dimer isolated from Nigella sativa seed's volatile oil) to children and adults in the treatment of bronchial asthma with effective results and with no sign of toxicity. In a clinical study, treatment of patients with allergic diseases, including allergic rhinitis, bronchial asthma, atopic eczema, with Nigella sativa oil decreased the IgE, and eosinophil count, endogenous cortisol in plasma and urine, indicating to effectiveness of Nigella sativa oil as adjuvant for the treatment of allergic diseases. ${ }^{22}$

In Fararh et al, 2004 investigated Nigella sativa oil exerted the potential immunopotentiating activity on peritoneal macrophage via activation of lymphocytes and macrophage in streptozotocin (STZ)-induced diabetic hamsters. These research results support the use Nigella sativa in folk medicine an antiinflammatory agent or remedy in intervention of diabetes and other metabolism diseases. ${ }^{23}$

Kocyigit et al., 2009 showed that Nigella sativa powdered seeds obviously decreased the total cholesterol and triglyceride levels, suggesting the good antihyperlipidaemia effect of Nigella sativa in male rats. ${ }^{24}$

Amin et al, 2009 in their study stated that, herbal mixture including black seed was found to have a distinct anti-obesity effect in overweight rats, together with antioxidant, hypolipidemic insulin sensitizing effects. ${ }^{25}$

In a clinical study by Bamosa et al, 2010, recruited patient with diabetes was given capsules containing Nigella sativa orally at three doses for 3 months. Nigella sativa caused significant reductions in fasting blood glucose and hemoglobina glucosilada, but there is no significant weight loss and side effect in either renal functions or hepatic functions throughout the study period. Nigella sativa has the 
potential benefits to manage glucose levels as a remedy for oral hypoglycaemic drug in type 2 diabetic patients. ${ }^{26}$

Tembhurne SV, 2014 in their review article stated that in the Unani traditional medicine, Nigella sativa seeds are utilized as a natural remedy that have the capacity to cure plenty of diseases, such as diarrhoea, dyslipidaemia, rheumatoid arthritis, dermatological diseases, and digestive disorders. ${ }^{27}$

In a clinical trial conducted by Asgary et al 2015., Nigella sativa was identified to have antihyperglycaemic and lipidlowering effects via inhibition of hepatic cholesterol synthesis and activation of low-density lipoprotein (LDL) receptors. ${ }^{28}$

Prabhakar et al, 2015 stated that Thymoquinone (TQ) from Nigella sativa seed has been reported to ameliorate the highfructose diet (HFD)-induced hyperlipidaemia and metabolic syndrome in diabetic rats. ${ }^{29}$

Hadi et al, in 2016 concluded in their research that two extracts from Nigella sativa prevented the diabetic rats from cardiovascular risk through inhibition of HMG-CoA reductase activity and antioxidant mechanisms. Thus, they found that Nigella sativa may be useful in developing a complementary medicine for cardiovascular duo to its hypolipidemic, antioxidant, and antiperoxidative activities. ${ }^{30}$

Majdalawieh AF et al, in 2016 provided a comprehensive, analytical review of the reported anti-cancer properties of Nigella sativa seed extracts. This review focused on analysing experimental findings related to the ability of Nigella sativa to exert anti-proliferative, pro-apoptotic, antioxidant, cytotoxic, anti-mutagenic, antimetastatic, and $\mathrm{NK}$ cytotoxic activity enhancing effects against various primary cancer cells and cancer cell lines. The molecular mechanisms of action and the signal transduction pathways implicated in the suppression of tumorigenesis by Nigella sativa were discussed. The major signalling pathway utilized by Nigella sativa to manifest its anti-cancer activity is the iNOS signalling pathway. This review underscored the recent developments that highlight an effective therapeutic potential of Nigella sativa to suppress tumour development, reduce tumour incidence, and ameliorate carcinogenesis. They summarized that, experimental findings reported in the last two decades strongly suggest that Nigella sativa fractions could serve, alone or in combination with known chemotherapeutic drugs, as effective agents to control tumour initiation, growth, and metastasis, and hence, treatment of a wide range of cancers. ${ }^{31}$

In a study by Ramalingam et al in 2017, Nigella sativa seeds were reported to have a benefit on lipid peroxidation and antiobesity by the qualitative determination of phytochemicals and its pharmacological activities detection. ${ }^{32}$

Pipalia PR et al, in 2016 conducted a study to investigate the effectiveness of turmeric with black pepper and Nigella sativa in Oral submucous fibrosis (OSMF). Forty OSMF patients were included and randomly divided into two groups. Study was performed as double-blind randomized design. Group A received turmeric with black pepper and group B received Nigella sativa, for 3 months. Clinical evaluation was done at every 15 days. Patients' serum superoxide dismutase (SOD) levels were assessed before and after treatment and also compared with healthy controls. The response to treatment was analysed using ANOVA, paired t-test, unpaired t-test. After the treatment group A and group B showed $3.85 \pm 0.22 \mathrm{~mm}$ and $3.6 \pm 0.07 \mathrm{~mm}$ improvement in mouth opening respectively $(\mathrm{p}<0.01) ; 87.90 \%$ and $78.91 \%$ reduction in burning sensation respectively $(\mathrm{p}<0.01)$; and $+0.62 \mathrm{U} / \mathrm{ml}$ and
$+0.74 \mathrm{U} / \mathrm{ml}$ improvement in serum SOD levels respectively $(\mathrm{p}<0.05)$. The maximum MO achieved was $8 \mathrm{~mm}$ and $7 \mathrm{~mm}$ in group A and B respectively. The mean pre-treatment SOD level for the controls and patients was $3.61 \pm 0.24 \mathrm{U} / \mathrm{ml}$ and $2.63 \pm$ $0.18 \mathrm{U} / \mathrm{ml}$ respectively. Hence, they concluded that Turmeric with black pepper and Nigella sativa improved mouth opening, burning sensation and SOD levels in the present OSMF study subjects. ${ }^{33}$

Koshak et al in 2017, performed a review to assess studies supporting the medicinal use of NS in asthma and to highlight future research priorities. Various medical databases were searched for the effects of NS and its active secondary metabolites in asthma inflammation and outcomes. There were fourteen preclinical studies describing multiple effects of NS in animal or cellular models of asthma including bronchodilation, anti-histaminic, anti-inflammatory, antileukotrienes and immunomodulatory effects. Furthermore, seven clinical studies showed improvements in different asthma outcomes including symptoms, pulmonary function and laboratory parameters. However, often these studies are small and used ill-defined preparations. In conclusion, NS could be therapeutically beneficial in alleviating airway inflammation and the control of asthma symptoms, but the evidence remains scanty and is often based on poorly characterised preparations. Accordingly, well-designed large clinical studies using chemically well characterised NS preparation are required. ${ }^{34}$

Imran et al, 2018 in a review article concluded that Thymoquinone, a major Nigella sativa's constituent can be used excellently in the research areas of new drug development remarkably to combat cancer cell progression. It effects various stages of cancer such as proliferation, migration and invasion. ${ }^{35}$

Mahboubi M, 2018 stated that the results of investigations on Nigella sativa seed fixed oil showed its therapeutic potential in treatment of sinusitis by its anti-inflammatory, antioxidant, antihistaminic, immunomodulator, antimicrobial and analgesic effects. The use of Nigella sativa seed fixed oil can inhibit the inflammation of sinuses and respiratory airways, microbial infections and finally help the patients suffering from clinical symptoms of sinusitis such as coryza, nasal congestion, headache, neck pain, earache and toothache. ${ }^{36}$

Erisgin Z et al, 2019, in their study aimed to investigate the protective effects of Nigella sativa oil (NSO) against liver damage due to intraperitoneal usage of carboplatin which is commonly used as a chemotherapeutic agent. The authors in their conclusive statement remarked that chemotherapeutics are some of the important treatment options for cancer patients, and their possible adverse effects and tissue damage are some of the most important problems. This study indicates that use of NSO before chemotherapeutic exposure has partial protective effects on liver tissue. ${ }^{37}$

Aisa et al, 2019, in their book compiled that Nigella plant has been regarded as an effective medicinal and edible herb worldwide, displaying considerable commercial value in pharmaceutical and food industries. The review article conducted an investigation of the relevant literature on Nigella sativa plant over the past decade, particularly focusing on the antidiabetic biology activities of Nigella sativa and its compounds. The seeds of Nigella sativa have various pharmacological effects on the interventions of diabetes, including antioxidation, antiinflammatory, antidiabetic, 
antihyperglycemic, and antihypertensive activities. Also, its effects on antitumor, liver protection, immune system, and memory improvement have been demonstrated in various studies. According to the literature, Nigella sativa could be proposed as a preventive and relieving complementary medicine or dietary supplement in metabolic diseases, especially in the intervention of diabetes. ${ }^{38}$

\section{ANTIMICROBIAL ACTION OF NIGELLA SATIVA}

Rogozhin EA et al in 2011 conducted an experiment on antifungal activity of Nigella sativa and they concluded that high antifungal activity of Nigella sativa defensins makes them promising candidates for engineering pathogen-resistant plants. 39

El-Nagerabi in 2012 had undertaken a study to evaluate the inhibitory effect of Hibiscus sabdariffa calyx extract at concentrations of 5, 7.5, 10 and $12.5 \mathrm{~g} / 100 \mathrm{ml}$ and Nigella sativa oil at concentrations of 1,2 and $3 \mathrm{ml} / 100 \mathrm{ml}$ on the growth and aflatoxin B1 production by Aspergillus parasiticus (CBS 921.7) and Aspergillus flavus (SQU 21) strains. The results suggested that $H$. sabdariffa calyx and Nigella sativa oil extracted from seeds had metabolic effects on aflatoxin biosynthesis pathway of both Aspergillus species and can be used as an effective biocontrol and non-toxic biopreservatives in food industry against aflatoxin contamination. ${ }^{40}$

Rath et al, in 2014 conducted a study to screen methanolic extracts of 26 commonly used Indian spices against nine species of uropathogenic bacteria (Enterococcus faecalis, Staphylococcus aureus, Acinetobacter baumannii, Citrobacter freundii, Enterobacter aerogenes, Escherichia coli, Klebsiella pneumoniae, Proteus mirabilis, and Pseudomonas aeruginosa), isolated from clinical samples of a tertiary care hospital for antibacterial activity. They found that the most effective 15 spices, having at least $25-29 \mathrm{~mm}$ as the size of the zone of inhibition, were Allium cepa, Brassica juncea, Cinnamomum tamala, Cinnamomum zeylanicum, Coriandrum sativum, Cuminum cyminum, Curcuma longa, Mentha spicata, Murraya koenigii, Nigella sativa, Papaver somniferum, Piper nigrum, $S$. aromaticum, Trachyspermum ammi, and Trigonella foenum for at least one of the Gram positive or Gram negative MDR bacterial strains used. 41

Nadaf $\mathrm{NH}$ et al, in 2015 conducted a study in which phytochemicals from Nigella sativa seeds were extracted in methanol and acetone. Anti-yeast activity of each extract was checked by agar well diffusion method against Saccharomyces cerevisiae NCIM 3495, Candida utilis NCIM 3496, and Candida albicans NCIM 3466. Further elucidation of anti-yeast activity was done by scanning electron microscopy (SEM). The identification of phytochemicals was done by using GC-MS and the antioxidant properties checked by using DPPH assay. The maximum anti-yeast activity was reported at $\mathrm{pH} 7$ and $30{ }^{\circ} \mathrm{C}$ temperature. Qualitative analysis of extracts revealed the presence of flavonoids, terpenoids, glycosides and tannin. Thus, these results confirmed the anti-yeast and antioxidant properties of compounds extracted from Nigella sativa seeds which might be useful for further technology development processes. ${ }^{42}$

Bakal SN et al, in 2017 performed a systematic review on the antimicrobial effect of Nigella sativa and remarked that the progressive rise in multidrug-resistant (MDR) bacterial strains poses serious problems in the treatment of infectious diseases. While the number of newly developed antimicrobial compounds has greatly fallen, the resistance of pathogens against commonly prescribed drugs is further increasing. This rise in resistance illustrates the need for developing novel therapeutic and preventive antimicrobial options. The medicinal herb Nigella sativa and its derivatives constitute promising candidates. In a comprehensive literature review (using the PubMed data base), the authors searched for publications on the antimicrobial effects of Nigella sativa particularly directed against MDR bacterial strains. In vitro studies published between 2000 and 2015 revealed that Nigella sativa exerted potent antibacterial effects against both Gram-positive and Gram-negative species including resistant strains. For instance, Nigella sativa inhibited the growth of bacteria causing significant gastrointestinal morbidity such as Salmonella, Helicobacter pylori, and Escherichia coli. However, Listeria monocytogenes and Pseudomonas aeruginosa displayed resistance against black cumin seed extracts. In conclusion, literature review revealed potent antimicrobial properties of Nigella sativa against MDR strains in vitro that should be further investigated in order to develop novel therapeutic perspectives for combating infectious diseases particularly caused by MDR strains. ${ }^{43}$

Ashraf S et al, 2018 conducted a research on biochemically identified Salmonella enterica of human and poultry origin $(\mathrm{n}=10)$ were confirmed by polymerase chain reaction. Susceptibility to antibiotics was determined by Kirby Bauer disc diffusion method. In-vitro anti-salmonella activity of Nigella sativa essential oil and extracts (aqueous and methanol) was determined against antibiotic resistant isolates by well diffusion and micro broth dilution method. Cytotoxic potential of Nigella sativa was observed by MTT assay. In S. enterica the highest resistance $(100 \%)$ was detected against nalidixic acid and ampicillin followed by ofloxacin (80\%), tetracycline, co-trimoxazole and amoxicillin (60\%), ciprofloxacin $(40 \%)$ and gentamicin (20\%). Methanol extract of Nigella sativa produced zone of inhibition from $35 \pm 1.00$ to $17 \pm 1.00$ with mean MIC value $>562.5 \pm 384.1 \mu \mathrm{g} / \mathrm{mL}$. Essential oil showed antibacterial activity with zone of inhibition from $20 \pm 1.00$ to $14 \pm 1.00 \mathrm{~mm}$ and mean MIC value $>1000.0 \pm 322.7 \mu \mathrm{g} / \mathrm{mL}$. Aqueous extract had no anti salmonella activity. MTT results showed more than 50 percent cell survival at concentrations $>625$ and $>1250 \mu \mathrm{g} / \mathrm{mL}$ for methanol extract and essential oil of Nigella sativa respectively; less than concentrations required for antisalmonella activity. ${ }^{44}$

Kiari FZ et al in 2018 conducted an in vitro evaluation of the antimicrobial activity of essential oil (EO) and methanol extract (ME) from Algerian Nigella sativa L. seeds against microbial strains isolated from the oral cavity of periodontal patients was performed. Twelve Gram-positive bacteria, eleven Gram negative bacteria and three microscopic fungi strains were isolated and identified. The antimicrobial activities of EO and ME were tested against Staphylococcus aureus, Staphylococcus epidermidis, Streptococcus pneumoniae, Enterococcus faecalis, Klebsiella pneumoniae, Proteus sp., Acinetobacter baumannii/calcoaceticus, Porphyromonas sp., Veillonella sp., Candida sp. and Saccharomyces sp. Remarkable efficiencies of the essential oil and methanol extract of Nigella sativa seeds collected from South Algeria against the growth of microbes isolated from the oral cavity of Periodontitis patients 
were elucidated by the microdilution method, while the agar well diffusion method did not reflect these results. This proves that several factors can influence the antimicrobial activity of these extracts, and these results must be reproduced by other studies (in vitro and in vivo) to support the hypothesis regarding the efficacy of Nigella sativa against oral pathologies. 45

\section{CONCLUSIONS}

The seeds of Nigella sativa and their oil have been widely used in Unani and Ayurveda. It along with its active constituent thymoquinone possesses a wide spectrum of activities like diuretic, antihypertensive, antidiabetic, anticancer, immunomodulatory, analgesic, antimicrobial, anthelmintic, analgesic, antiinflammatory, spasmolytic, bronchodilator, gastroprotective, hepatoprotective, renal protective and antioxidant properties. Its potent antimicrobial properties especially can be utilized in various infections since herbal medicinal drugs offer better prospects in the backdrop of emerging antibiotic resistance.

Financial or Other Competing Interests: None.

\section{REFERENCES}

[1] Ahmad I, Chattopadhyay D, Khan MS. New look to phytomedicine: advancements in herbal products as novel drug leads. Academic Press 2019.

[2] Mosihuzzaman M, Choudhary MI. Protocols on safety, efficacy, standardization, and documentation of herbal medicine (IUPAC Technical Report). Pure and Applied Chemistry 2008;80(10):2195-230.

[3] Farnsworth NR, Bingel AS. Problems and prospects of discovering new drugs from higher plants by pharmacological screening. In: Wagner HK, Wolff PM, eds. New natural products and plant drugs with pharmacological, biological or therapeutical activity. Berlin Heidelberg: Springer-Verlag 1977:1-22.

[4] Miller LG. Herbal medicinals: selected clinical considerations focusing on known or potential drug-herb interactions. Arch Intern Med 1998;158(20):2200-11.

[5] Vickers A, Zollman C. ABC of complementary medicine: herbal medicine. BMJ 1999;319(7222):1422.

[6] Taylor L. Plant based drugs and medicines. Rain tree Nutrition Inc 2000:1-5.

[7] Fabricant DS, Farnsworth NR. The value of plants used in traditional medicine for drug discovery. Environ Health Perspect 2001;109(Suppl 1):69-75.

[8] Maurya R, Singh G, Yadav PP. Antiosteoporotic agents from natural sources. Studies in Natural Products Chemistry 2008;35:517-48.

[9] Martinez MJA, Lazaro RM, Del Olmo LMB, et al. Antiinfectious activity in the anthemideae tribe. Studies in Natural Products Chemistry 2008;35:445-516.

[10] WHO. Media Centre, Traditional medicine. World Health Organisation 2008.

[11] Benkaci-Ali F, Baaliouamer A, Meklati BY, et al. Chemical composition of seed essential oils from Algerian Nigella sativa extracted by microwave and hydrodistillation. Flavour and Fragrance Journal 2007;22(2):148-53.

[12] Cheikh-Rouhou S, Besbes S, Hentati B, et al. Nigella sativa L.: Chemical composition and physicochemical characteristics of lipid fraction. Food Chemistry 2007;101(2):673-81.

[13] Hamrouni-Sellami IB, Kchouk ME, Marzouk B. Lipid and aroma composition of black cumin (Nigella sativa L.) seeds from Tunisia. Journal of Food Biochemistry 2008;32(3):335-52.

[14] Kooti W, Hasanzadeh-Noohi Z, Sharafi-Ahvazi N, et al. Phytochemistry, pharmacology, and therapeutic uses of black seed (Nigella sativa). Chin J Nat Med 2016;14(10):732-45.

[15] Takruri HRH, Dameh MAF. Study of the nutritional value of black cumin seeds (Nigella sativa L). Journal of the Science of Food and Agriculture 1998;76(3):404-10.

[16] Cheikh-Rouhou S, Besbes S, Hentati B, et al. Nigella sativa L.: Chemical composition and physicochemical characteristics of lipid fraction. Food Chemistry 2007;101(2):673-81.

[17] Sun L, Liu YM, Chen BQ, et al. New phenolic compounds from the seeds of Nigella glandulifera and their inhibitory activities against human cancer cells. Bioorg Med Chem Lett 2015;25(18):3864-6.

[18] Chen QB, Xin XL, Aisa HA. Pyrrolo-isoquinoline and glycosylated pyrrolidine alkaloids from Nigella glandulifera and their anti-PTP1B activity. Phytochemistry Letters 2017;19:168-71.

[19] Saxena SN, Rathore SS, Diwakar Y, et al. Genetic diversity in fatty acid composition and antioxidant capacity of Nigella sativa L. genotypes. LWT 2017;78:198-207.

[20] Arroo RRJ, Alfa HH. Chemical properties of thymoquinone, a monoterpene isolated from the seeds of Nigella sativa Linn. Pharmacol Res 2018;133:151.

[21] Ramadan MF, Kroh LW, Mörsel JT. Radical scavenging activity of black cumin (Nigella sativa L.), coriander (Coriandrum sativum L.), and niger (Guizotia abyssinica Cass.) crude seed oils and oil fractions. J Agric Food Chem 2003;51(24):6961-9.

[22] Kalus U, Pruss A, Bystron J, et al. Effect of Nigella sativa (black seed) on subjective feeling in patients with allergic diseases. Phytotherapy Research: An International Journal Devoted to Pharmacological and Toxicological Evaluation of Natural Product Derivatives 2003;17(10):1209-14.

[23] Fararh KM, Atoji Y, Shimizu Y, et al. Mechanisms of the hypoglycaemic and immunopotentiating effects of Nigella sativa L. oil in streptozotocin-induced diabetic hamsters. Res Vet Sci 2004;77(2):123-9.

[24] Kocyigit Y, Atamer Y, Uysal E. The effect of dietary supplementation of Nigella sativa L. on serum lipid profile in rats. Saudi Med J 2009;30(7):893-6.

[25] Amin KA, Nagy MA. Effect of carnitine and herbal mixture extract on obesity induced by high fat diet in rats. Diabetol Metab Syndr 2009;1(1):17.

[26] Bamosa AO, Kaatabi H, Lebdaa FM, et al. Effect of Nigella sativa seeds on the glycemic control of patients with type 2 diabetes mellitus. Indian J Physiol Pharmacol 2010;54(4):344-54. 
[27] Tembhurne SV, Feroz S, More BH, et al. A review on therapeutic potential of Nigella sativa (kalonji) seeds. J Med Plants Res 2014;8(3):167-77.

[28] Asgary S, Sahebkar A, Goli-Malekabadi N. Ameliorative effects of Nigella sativa on dyslipidemia. J Endocrinol Invest 2015;38(10):1039-46.

[29] Prabhakar P, Reeta KH, Maulik SK, et al. Protective effect of thymoquinone against high-fructose diet-induced metabolic syndrome in rats. Eur J Nutr 2015;54(7):111727.

[30] Hadi S, Mirmiran P, Hadi V, et al. Effects of Nigella sativa on cardiovascular risk factors. J Mazandaran Univ Med Sci 2016;25(134):430-42.

[31] Majdalawieh AF, Fayyad MW. Recent advances on the anti-cancer properties of Nigella sativa, a widely used food additive. J Ayurveda Integr Med 2016;7(3):173-80.

[32] Ramalingam PS, Raj MAS, Ravichandran P, et al. Lipid peroxidation and anti-obesity activity of Nigella sativa seeds. World J Pharma Res 2017;6(10):882-92.

[33] Pipalia PR, Annigeri RG, Mehta R. Clinicobiochemical evaluation of turmeric with black pepper and Nigella sativa in management of oral submucous fibrosis-a double-blind, randomized preliminary study. Oral Surg Oral Med Oral Pathol Oral Radiol 2016;122(6):705-12.

[34] Koshak A, Koshak E, Heinrich M. Medicinal benefits of Nigella sativa in bronchial asthma: a literature review. Saudi Pharm J 2017;25(8):1130-6.

[35] Imran M, Rauf A, Khan IA, et al. Thymoquinone: a novel strategy to combat cancer: a review. Biomedicine \& Pharmacotherapy 2018;106:390-402.

[36] Mahboubi M. Natural therapeutic approach of Nigella sativa (Black seed) fixed oil in management of Sinusitis. Integr Med Res 2018;7(1):27-32.

[37] Erisgin Z, Atasever M, Cetinkaya K, et al. Protective effects of Nigella sativa oil against carboplatin-induced liver damage in rats. Biomedicine \& Pharmacotherapy 2019;110:742-7.

[38] Aisa HA, Xin XL, Tang D. Nigella sativa: a medicinal and edible plant that ameliorates diabetes. In: Watson RR, Preedy VR, eds. Bioactive food as dietary interventions for diabetes. Academic Press 2019:629-40.

[39] Rogozhin EA, Oshchepkova YI, Odintsova TI, et al. Novel antifungal defensins from Nigella sativa L. seeds. Plant Physiol Biochem 2011;49(2):131-7.

[40] El-Nagerabi SA, Al-Bahry SN, Elshafie AE, et al. Effect of Hibiscus sabdariffa extract and Nigella sativa oil on the growth and aflatoxin B1 production of Aspergillus flavus and Aspergillus parasiticus strains. Food Control 2012;25(1):59-63.

[41] Rath S, Padhy RN. Monitoring in vitro antibacterial efficacy of 26 Indian spices against multidrug resistant urinary tract infecting bacteria. Integrative Medicine Research 2014;3(3):133-41.

[42] Nadaf NH, Gawade SS, Muniv AS, et al. Exploring antiyeast activity of Nigella sativa seed extracts. Industrial Crops and Products 2015;77:624-30.

[43] Bakal SN, Bereswill S, Heimesaat MM. Finding novel antibiotic substances from medicinal plantsantimicrobial properties of Nigella sativa directed against multidrug resistant bacteria. Eur J Microbiol Immunol 2017;7(1):92-8.

[44] Ashraf S, Anjum AA, Ahmad A, et al. In vitro activity of Nigella sativa against antibiotic resistant Salmonella enterica. Environ Toxicol Pharmacol 2018;58:54-8.

[45] Kiari FZ, Meddah B, Meddah AT. In vitro study on the activity of essential oil and methanolic extract from Algerian Nigella sativa L. Seeds on the growth kinetics of micro-organisms isolated from the buccal cavities of periodontal patients. The Saudi Dental Journal 2018;30(4):312-23. 